\title{
PROFESSIONAL BURNOUT OF CHILD PSYCHOLOGISTS AND EDUCATORS OF CEI
}

https://doi.org/10.37096/SHDISJ-20-2.2-0002

\author{
Viktoriia Davydenko \\ ORCID ID: 0000-0001-9214-2855
}

\begin{abstract}
The article considers the problem of professional burnout and its connection with the working atmosphere of child psychologists and educators of CEI. The professional range of work of child psychologists and educators of CEI is revealed and compared. Professional burnout is shown in the context of the employee's interaction with the coworkers and its impact on the quality of work. The comparison revealed the phase of the burnout syndrome at the stage of the formation, which means that workers are in the state of stress, which depends on external influences.

It was justified that the professional burnout of psychologists and educators of CEI is manifested mostly in the following phenomena: depersonalization, apathy, depression, pessimism, nervous breakdowns and the fear of not coping with their responsibilities. Organizational and methodological aspects of the research are described. Probationers in this study were women of different ages, child psychologists and educators of CEI. Empirical study of the influence of the syndrome of their burnout was conducted in various development centers and children's educational institutions. In winter 2020, 18 persons were interviewed and 22 persons took part in a study during the spring quarantine, caused by COVID-19, in conditions of self-isolation. In particular, the level of professional burnout was determined by using the method of V.V.Boyko "Diagnosis of the level of emotional burnout" (Boyko, 2009). To highlight the psychological factors of burnout and study the impact of working atmosphere on burnout of psychologists and educators of CEI, the method of assessing organizational culture K. Cameron, R. Quinn (Kim S. Cameron, Robert E. Quinn, 2011), the method PsyCapQuestionnaire (PCQ) Luthans, F., Avolio, B., Avey, J., \& Norman, S. (F Luthans, B. J. Avolio, J. B. Avey, and S. M. Norman, 2007), "Attitude to work" (Trofimov, Milutina, 2020) and "Communicative Tolerance" (Boyko, 1998) was used.

The study did not reveal the formed phases of the burnout syndrome; relations in the team between co-workers are satisfied, the assumption that a significant impact on the syndrome of "professional burnout" has a working atmosphere was not confirmed. In this regard, we assume that a possible obstacle to confirm the previous assumption about the influence of the working atmosphere on burnout was that the major part of the probationers was already self-isolated due to COVID-19.
\end{abstract}

Keywords: burnout syndrome, professional burnout, emotional burnout.

\section{Introduction}

The first work on burnout belongs to the American
J. Freidenberger, who introduced a new term to describe the psychological state of individuals in an emotional, stressful 
atmosphere in the provision of professional care. Later, the problem of emotional burnout was examined more detailed by K. Maslach, who proposed a new term to denote this phenomenon "burnout" ("burnout"), which means a process.

In their study A. Payson \& E. Ironson (1988) proposed one-factor model that considered exhaustion as the main consequence of emotional burnout, and the manifestations of disharmony, feelings and behavior were its secondary consequences. It was given an attention to the relationship between motivation and burnout, generally highlighting the following motives: salary satisfaction, a sense of importance, needs in the workspace, career growth and promotion, interpersonal development and so on. They did not find a direct connection between burnout and the level of wages (Udovik S., Molokoidov A., Slobidchikov I., 2018: 9-26).

Improper operation is manifested in the workload, which contributes to burnout, repeatedly becoming its cause. There is a close connection between burnout (especially emotional exhaustion) and workload. At the workplace workload leads to emotional exhaustion, which is manifested in excessive demands on employees, which exhaust them. It can be not only amount of work but also a lack of necessary skills, knowledge to do the work. Then, as a result of the lack of competence, the workload increases and that may cause the inability to do the work (Maslach et. al., 2001).

Burnout of psychologists can cause ethical problems, which lead to the continuation and completion of their work (Rupert et. al., 2015). There is a clear state in the Canadian psychological ethical code: «engage in self-care activities that help avoid conditions» (for example, burnout). So, the syndrome can lead to violation of one's own judgments and obstruct the employee from benefiting (Koocher \& Keith-Spiegel, 2008). Therefore, it is clear that burnout is a potential personal problem that can negatively affect the competence, perception of self-concept, so it should be considered by ethical standards.

The relevance of the problem is in the fact that the syndrome mostly affects those who work with the human factor. This factor includes: communication, transmission and reception of any information, including emotions. Emotions can be depleted and this leads to emotional exhaustion, which is appearing in feelings of emotional stress and feeling of emptiness. A person feels that cannot do his work with the same inspiration and desire as before.

Rupert and co-workers (Rupert et al. 2009) believe that burnout can negatively affect the quality of their work, and therefore the quality of the service provided to customers may not be reliable enough. Thus, burnout is not only harmful to the employee (for example, a psychologists or educator), but can also have a secondary detrimental effect on the individual during the work process.

The professional work of child psychologist and educators of CEI is similar. It is focused on children, their development and communication with parents. The work structure of both professions, at first glance, is the same. But actually, the difference is significant. The child psychologists help parents to solve problems and difficulties, which appear during the process of growing up and development of children and in relationships between parents and children. Psychologists work with 
occurrence of problems, which have psychological character. The working team of child psychologists may include specialists of various psychological fields and, as practice shows, during nonworking hours or between breaks it is possible to have some discussions. If there are difficulties in the working process, it is possible to get support or supervision, which is obligatory in the profession of psychologists. Supervision can prevent the symptoms of burnout. The work of educators of CEI is associated with educational work: to conduct classes, games and, in general, to organize the stay of children in educational institutions. The team and the atmosphere in this profession consists of constant stay with children during the working day, so time to communicate with co-workers is generally small. Also, educators of CEI cannot always prevent the symptoms of burnout due to insufficient communication with psychological care professionals.

Therefore, analyzing the differences between the studied groups, we can say that psychologists have a more favorable working atmosphere to prevent symptoms of burnout. This includes more often breaks, an ability to have discussions between co-workers and receiving recommendations unlike working atmosphere of educators of CEI.

The purpose of the article is empirically investigate the manifestations of the syndrome of "professional burnout" of psychologists and educators of CEI and identify the impact of the working atmosphere on the manifestations of the syndrome.

\section{Theoretical background}

The problem of the professional burnout syndrome has been studied in the works of foreign and domestic scientists.
The content and structure of the syndrome were examined by L. M. Karamushka, S. D. Maksimenko, T. V. Zaichikova. The methods of its diagnosis were reviewed by V.V. Boyko, N.E. Vodopyanova. Peculiarities of professional stress, some manifestations of the syndrome of professional burnout, its causes and consequences of educators of CEI, were studied by (A. A. Rean, A. A. Baranov, 1997), (L. O. Kitaev-Smyk, 2015), (Y. L. Lviv, 1988) and others.

At each stage of work an educator of CEI, as well as a psychologist, has its own characteristics that affect the psychoemotional state of employees. In a study by Bearse and co-authors (Bearse et al., 2013), it was found that one of the barriers for psychologists, who need a professional help, there is an idea that it's hard to find this help. Almost $60 \%$ of respondents stated that they did not ask for help, although they were aware that they could benefit from this time (Bearse et al. 2013: 150-157).

As Schaufeli W. B. noted, at the organizational level there are appearing similar negative perceptions of colleagues and managers, and an excessively critical attitude towards people is formed. This may lead to aggressive behavior, towards colleagues (Maslach, C., Schaufeli, W. B., \& Leiter, M. P., 2001).

The main psychological problem of those, who work with children, is connected with a state of stress with necessity of the need for internal adjustment to a certain behavior, mobilizations of energy for active and expedient actions. Researchers believe that the syndrome of "professional burnout" is mostly common for people with 11-16 years of experience (Maslach, C., Schaufeli, W. B., \& Leiter, M. P., 2001: 397-422). 
In the analyzed literary sources it was found that serious manifestations of "professional burnout" are behavioral changes and rigidity. Normally talkative and unrestrained person can become quiet and alienated. On the contrary, usually quiet and reserved person can become very talkative, join a conversation with anyone. An employee with burnout syndrome may become rigid in thinking. A rigid worker is closed to changes because they require energy and risk, which are threatening to an already exhausted person. Violations determine the formation of the symptom complex. It may include different indicators, which have a great influence on the destruction of the personality of specialists. Workers are not able to take full advantage of their professional opportunities because they experience a state of mental fatigue or lose their working skills.

The research of the impact of emotional burnout is very important for those, who work with children. The study of this syndrome and creation of conditions to prevent its formation can contribute a positive atmosphere in educational and consultative process.

\section{Methodology}

The profession of educator of CEI is related to the development of the child. The same applies to the child psychologist. The development of children's attention, memory, thinking, ingenuity, initiative, communication skills etc., - are the part of the function of employees. Contact with parents and colleagues - is integral part as well. All this requires a lot of energy and strength and then acquires a permanent character and leads to exhaustion. According to the topic and purpose, the following methods are chosen:
1) Method of diagnosing the level of emotional burnout V. V. Boyko (Boyko, 2009).

This method is the most complex. It provides an opportunity to analyze systematically and in detail the severity of the twelve symptoms of burnout syndrome, including components to which they relate. It consists of 84 items; each includes two judgments of a value or behavior nature. It allows determining at what stage of the formation of "emotional burnout" with the help to these components, such as:

1. Stress, which is characterized by a feeling of emotional exhaustion, fatigue caused by their own professional activities.

It can cause such symptoms as the perception of working conditions and professional interpersonal relationships as psycho-traumatic; dissatisfaction with one's personal professional activity and oneself as a professional; feeling of hopelessness and a desire to change work or professional activity in general, there may also be increased nervousness and depressed mood.

2. Resistance, which is characterized by excessive emotional exhaustion, provokes the formation and development of protective reactions that make person emotionally closed and detached. At this background, any emotional involvement in professional deeds and communications makes a person to feel an excessive fatigue. It can manifest in such symptoms as an inadequate selective emotional response; presence of emotional and moral disorientation; a reduction of professional duties.

3. Exhaustion, characterized by psychophysical fatigue of a person, feeling of emptiness, depreciation of 
one's own professional skills and achievements, violations of professional communications, the development of cynical attitude towards co-workers, formation of psychosomatic disorders. It can cause such symptoms as: emotional deficiency; emotional alienation; personal alienation (depersonalization); psychosomatic and psycho-vegetative disorders.

2) Assessment of organizational culture by K. Cameron and R. Quinn (Kim S. Cameron, Robert E. Quinn, 2011).

This questionnaire provides an opportunity to identify the type of organizational culture of the employee. Based on the results of the completed questionnaire, it is possible to assess six most important parameters of culture: the dominant characteristics of the organization's culture; leadership style that permeates the entire organization; management of employees; the coherence of the organization or the mechanisms that allow employees to stay together, the strategic accents that determine which business processes are key to the implementation of the organization's strategy; success criteria.

There are also six standard sections of comparison in the organization: for today's dominant type of culture; differences between current and desired future culture; the power of the dominant type of culture; the consistency of the profiles of different attributes of the culture and different individual assessments of these attributes by the members of the organization; according to the results of comparison of the culture profile of the organization with the average culture profile; compatibility of the tendencies of the organization with a number of general tendencies of the development of the economic space.

3) Methodology "Attitude to work" (Trofimov A., Milyutina K., 2020: 233236).

The method is based on the principle of bipolar semantic differential, which allows us to explore the presence of a general indicator of the attitude to work and individual components; stability, effectiveness, relationships with the team, discipline.

4) Methods for the study of psychological capital of employees (PCQ), Luthans F., Avolio B., Avey J., Normans S. (Luthans F., Avolio B., Avey J., Normans S., 2007).

This method is created to study a psychological capital.

5) Questionnaire of communicative tolerance V.V. Boyko (Boyko, 1998). This questionnaire allows assessing in which aspects of the relationships there is a greatest propensity for conflict. It makes it possible to identify behavioral reactions, strategies and attitudes in interpersonal communication, which need to be adjusted to make the communication process pleasant and effective.

Each of these methods makes it possible to identify a separate indicator of the working atmosphere, which, as we assume, contributes the formation of the burnout syndrome.

The study involved 40 people: 18 psychologists from various development centers and 22 educators of CEI. These centers and institutions of children education were within the Kyiv region. The study was conducted from winter until the spring of 2020 .

The solution of the tasks was carried out with the help of theoretical and 
empirical methods: the first stage - the theoretical - provided for the definition of the essence and peculiarities of the influence on the personality of the psychologist and educator of CEI of the syndrome of "professional burnout"; the second stage - empirical - determination of the influence of personal and organizational factors on the syndrome of psychological burnout of psychologists and educators of CEI.

\section{Results}

To verify the existence of statistically significant differences in the features of professional burnout among educators of CEI and child psychologists, a nonparametric criterion was used to compare the independent Mann-Whitney variables. Due to its application, the hypothesis of the existence of a statistically significant difference between the groups of educators of CEI and child psychologists was not confirmed.

Analyze of the results of the survey according to the method of V. Boyko "Diagnosis of the level of emotional burnout" (Table 1). The indicator of "emotional burnout" on a scale "Stress" is 31.8 , which means that a phase is not formed. The indicator is 49.9 on a scale "Resistance" that means a phase of formation. The scale "Exhaustion" shows 39.6 that also means a phase of formation. There were no general formed phases.

Table 1. The average standard deviation of the indicators of the method of V.V. Boyko "Diagnosis of the level of emotional burnout" and the method (PCQ)

\begin{tabular}{|c|c|c|c|}
\hline \multirow{2}{*}{ Variable name } & \multicolumn{3}{|c|}{ Average values } \\
\cline { 2 - 4 } & $\begin{array}{l}\text { General values of } \\
\text { groups }\end{array}$ & $\begin{array}{l}\text { Educators of } \\
\text { CEI }\end{array}$ & Psychologists \\
\hline Stress & 31,8 & 32,5 & $\mathrm{n}=18$ \\
\hline Resistance & 49,9 & 52,3 & 46,9 \\
\hline Exhaustion & 39,6 & 42,1 & 36,5 \\
\hline Effectiveness & 22,6 & 23,2 & 21,8 \\
\hline Hope & 22,2 & 23,5 & 20,7 \\
\hline Resilience & 21,8 & 21,8 & 21,7 \\
\hline Optimism & 20,0 & 20,8 & 19,0 \\
\hline Feedback & 10,0 & 10,0 & 10,0 \\
\hline
\end{tabular}

Thus, we found that the formed phases of the syndrome are absent and the phase of resistance is in the stage of formation, which indicates excessive emotional stress in the groups of "psychologists" and "educators of CEI".

According to the indicators of the PCQ method, we have found that resilience has the same manifestation in two professional fields, which means high (21.8) resilience to external influences and the ability to store and reveal the skills for a long time. Feedback indicator is 10 , which corresponds to its presence. Effectiveness is more manifested in the group of educators than in the group of psychologists. Based on this, it can be argued that educators are more focused on 
the effectiveness of the process (for example, educational). The indicator of hope is also higher in the group of educators (23.5), which is a sign of greater commitment in their faith of work. But the indicator of optimism occupies almost the same degree of expression (20). It means faith in the future and the achievement of their goals.

Evaluation of organizational culture according to the method of Cameron K., Quinn R. (Kim S. Cameron, Robert E. Quinn, 2011) makes it possible to evaluate organizational culture by individual parameters. Thus, a comparison of average values by types of organizational cultures was made, namely:

- Psychologists have higher indicators of the desired clan (78.5), lower indicators in the organizational real clan (56.1).

- Educators have higher indicators of the desired clan (85.5), lower indicators of the adhocratic real (54.4).

Thus, for a group of "educators of CEI" the typical type is the desired organizational culture, the real type is democratic.

And for the group of "psychologists" the desired and real type of clan organizational culture is typical.

According to the results of the method "Communicative tolerance" V.V. Boyko, educators noticed tolerance (59.4) according to the general indicators, which means an average degree (Table 2). The indicator for psychologists was (56.1), which also corresponds to the average indicators.

The lower the rate, the higher the degree of tolerance, so the general rate of tolerance is manifested more in the group of psychologists. This means tolerance and a higher level of communicative tolerance in this aspect of relations.

Table 2. The results of the study by the method of "Communicative tolerance" by VV Boyko and the method of "Attitude to work"

\begin{tabular}{|c|c|c|c|}
\hline $\begin{array}{c}\text { Name of the } \\
\text { method }\end{array}$ & Variable name & $\begin{array}{c}\text { Average } \\
\text { values of the } \\
\text { group of } \\
\text { educators }\end{array}$ & $\begin{array}{c}\text { Average } \\
\text { values of the } \\
\text { group of } \\
\text { psychologists }\end{array}$ \\
\hline $\begin{array}{c}\text { "Communicative } \\
\text { tolerance" V.V. Boyko }\end{array}$ & Tolerance & 59,4 & 56,1 \\
\hline \multirow{2}{*}{ Attitude to work } & Stability & 17,1 & 14,8 \\
\cline { 2 - 4 } & Effectiveness & 16,5 & 15,4 \\
\cline { 2 - 4 } & $\begin{array}{c}\text { Relationships } \\
\text { with colleagues }\end{array}$ & 15,2 & 12,7 \\
\cline { 2 - 4 } & Discipline & 15,8 & 15,5 \\
\hline
\end{tabular}

The results of the method "Attitude to work" indicate that the highest score is the amount that is closest to 25 . If you compare the stability, it is higher in educators (17.1) than in psychologists. Relationships with colleagues are better in 
the group of educators than psychologist based on the general indicator of educators (15.2) and psychologists (12.7). Discipline at work is found to be the same in these professional fields. We assume that under the same number of probationers the result would be almost the same.

Table 3. Correlation between the methods of "Diagnosis of the level of emotional burnout" V.V. Boyko and the PCQ

\begin{tabular}{|l|l|l|l|l|l|}
\hline \multicolumn{1}{|c|}{$\begin{array}{c}\text { PCQ } \\
\text { Burnout }\end{array}$} & Effectiveness & Hope & Resilience & Optimism & Feedback \\
\hline Stress & 0,135 & 0,131 & $-0,502^{* *}$ & $-0,230$ & $-0,278$ \\
\hline Resistance & 0,079 & 0,147 & $0,315^{*}$ & $0,471^{* *}$ & $-0,055$ \\
\hline Exhaustion & $-0,282$ & 0,252 & $-0,385^{*}$ & $-0,216$ & 0,185 \\
\hline
\end{tabular}

According to these indicators, which are listed in table 3 , we can conclude that there is a direct relationship between the scale of resistance and optimism (P-value $=0.471, \mathrm{p}=0.05)$, this may be due to the fact that the positive atmosphere has a strong direct correlation with the emergence of the development of protective reactions. The resistance scale also has a direct correlation with the stability (P-value $=0.315)$, the logical explanation is because a more stable worker is less conducive to irritation, while the resistance has a very weakly indirect correlation with the stress scale $(\mathrm{P}$-value $=-0.502)$. In my opinion, this may indicate a feature of the structure of the working process.

Table 4. Correlation between methods of "Diagnosis of the level of emotional burnout" and "Communicative tolerance" V.V. Boyko

\begin{tabular}{|l|l|}
\hline Burnout & \\
\hline Stress & Tolerance \\
\hline Resistance & 0,072 \\
\hline Exhaustion & $0,390^{*}$ \\
\hline
\end{tabular}

The statistical significance between burnout and tolerance was revealed (Table 4). Indicators of the resistance scale $(\mathrm{P}$-value $=0.390)$, where the limit of $\mathrm{P}$-value $=0.05$, indicate that emotional secrecy has an impact on communication, or rather adaptation, evaluation, regulation of emotions. There is no direct correlation between the scale of exhaustion and tolerance $(\mathrm{P}$-value $=$ $0.024)$, there is an assumption that the mechanisms of communicative tolerance, namely the ability to restrain negative reactions, to adequately assess the significance of the situation are not directly related to fatigue.

\section{Discussion}

Psychological resilience depends on the level of stress, the formation of the phase of resistance depends on optimism, because less often "burn out" optimistic and cheerful people, who know how to overcome life's hardships and age crises, those, who occupy difficult 
circumstances, possess the means of mental self-regulation, take care of replenishment of their psycho-energetic and social-psychological resources. The connection between the phase of resistance and tolerance is explained by the fact that the resistance of employees is related to the degree of endurance of unpleasant or unacceptable, in their opinion, mental states, qualities and actions (team or object) of interaction.

It should be noted that employees, who had a high level of support from managers and colleagues have a less manifested tendency to burn out (Wade et al., 1986). So, it becomes clear why the probationers have high performance in the organizational culture they would like to have. In both groups, the organizational culture of the clan is desirable, which is characterized by focusing on caring for people and internal respect for the individuality and uniqueness of each, team cohesion, support and coherence.

In the research of Starchenkova E. and Vodopyanova N. (2008) it was studied the relationship between burnout, optimism and active life positions, it was found that active optimists in comparison with realists have less tendency to burn out, the correlation showed that the higher the activity and optimistic attitudes to life, the less emotional exhaustion.

According to the results of our study, we can add that the optimistic atmosphere has a strong direct correlation with the occurrence of protective reactions in employees.

The limitation of this study is that the number of probationers is not enough for reliability. In the future, it would be appropriate to increase the sample and conduct a repeat study. The results of the study could also be influenced by the conditions of self-isolation in connection with COVID-19, because the hypothesis of the study was to identify the impact of the working atmosphere on burnout, but compliance with self-isolation conditions means the avoidance of contact with others.

In this research it was revealed that the relationship in the team between coworkers is average. The "Diagnosis of the level of emotional burnout" (Boyko, 2009) showed that the phase of "resistance" is in formation, which is a sign of the emotional tone decrease and the protection from unpleasant impressions of educators of CEI. So, it is more likely that burnout is more related to the employee-client relationships than to the manager-subordinate relationship. The phase of "strain" is in an unformed state in both groups, the results are almost the same (32.5) educators of CEI and (31) for psychologists. Indicators of the phase "exhaustion" for the psychologists (36.5) can be attributed to the unformed phase and for educators (42.1) are already at the stage of formation.

A typical type of desired organizational culture for a group of "educators of CEI" is a type, where the manager is able to be a leader and can find and individual approach to each employee. The real type is adhocratic, strict rules are absent, the main things are skills, power depends more on the knowledge of deeds and abilities than on the position. The desired and real organizational culture for the group of "psychologists" is the type of clan. In this type knowledge is more important than a position. 


\section{Conclusion}

The workers did not have any formed phases of "emotional burnout", so it can be affirmed that they need preventive measures to prevent the syndrome.

Relationships with the team have a satisfactory performance, so its effect on the syndrome is unlikely. We did not confirm the assumption that the working atmosphere has a significant effect on the syndrome of "professional burnout". A possible explanation for this effect is conditions of self-isolation in connection with COVID-19.

Prevention and correction of mental burnout should include training the individual in the skills of adequate emotional response to

\section{References}

Bearse J.L., McMinn, M. R., Seegobin, W., \& Free, K. (2013). Barriers to psychologists seeking mental health care. Professional Psychology: Research and Practice, 44 (3), 150157.

https://doi.org/10.1037/a0031182

Boyko V.V. (1999) Syndrome of "emotional burnout" in professional communication.

$\mathrm{SPb}$. Peter.

Bulatevich NM (2005). Emotional burnout syndrome: the role of individual and organizational factors. Bulletin of the Taras Shevchenko National University of Kyiv. Sociology series. Psychology. Pedagogy. V ip. 22-23. P.47-50.

Van Droogenbroeck F., Spruyt B., \& Vanroelen C. (2014). Burnout among senior teachers: Investigating the role of workload and circumstances. Important for the prevention of the syndrome of "professional burnout" are the skills of self-control, the ability to work with their own negative emotions, the ability to feel free. The following methods were chosen for the training: group supervision, discussion, role-playing games, discussion of specific situations, exercises for practicing skills and abilities focused on the reflexive thinking.

The prospect for the further development of this problem may be the identification of professional orientation in child psychologists and educators of CEI. It is possible to assume the similarity of their professional tasks and goals.

interpersonal relationships at work. Teaching and Teacher Education, 43, 99-109. https://doi.org/10.1016/j.tate.2014.0 7.005

Dziuba K. (2013) Prevention of burnout: a set of exercises for emotional stability. Psychologist. № 8. pp. 2425

Freudenberger, H. J. (1975). The staff burn-out syndrome in alternative institutions. Psychotherapy: Theory, Research \& Practice, 12(1), 73-82. https://doi.org/10.1037/h0086411

Kitaev-Smyk L.A (Ed.) (2015). Consciousness and stress: Creativity. Mastery. Burnout. Neurosis M.: Meaning.

Koocher GP, Keith-Spiegel P. (2008). Ethics in Psychology and the Mental Health Professions: Standards and Cases (3rd e d.). New York: Oxford University Press. Reviewed by Eric K. Willmarth, PhD, Saybrook 
Graduate School and Research Center, San Francisco, CA. and Western Michigan University, Kalamazoo, MI

https://doi.org/10.1080/00029157. 2009.10401695

Kotlyarenko I.O. (2019). Determinants of professional burnout of kindergarten teachers. Current problems of psychology. T.12. Psychology of creativity. Issue 19. P.37-45.

Maksimenko S.D., Karamushka LM, Zaychikova T.V. (2006). Professional burnout and professional careers of educational organizations: gender aspects. $\mathrm{K}$.: Millennium.

Malinowski A. J. (2013). Malinowski, A. J. (2013). Characteristics of job burnout and humor among psychotherapists. Humor: International Journal of Humor Research, 26(1), 117-133. https://doi.org/10.1515/humor2013-0007

Maslach, C., Schaufeli, W. B., \& Leiter, M. P. (2001). Job burnout. Annual Review of Psychology, 52, 397-422. https://doi.org/10.1146/annurev.psy ch.52.1.397

Milyutina K.L, Trofimov A.Yu. (2020). Psychology of modern business. Kyiv: Lira.

Molokoedov A.V., Udovik S.V., Slobodchikov I.M. (2016) Emotional burnout in professional activities. Moscow: Lev.

Nekiz T.A. Prevention of emotional burnout of a psychologist in the process of working with deviant adolescents. Current problems of psychology. Volume XI. Issue 13. P.171-177.

On the question of the decline in the professional activity of teachers and its tides. Socio-pedagogical problems of professional and social activity of teachers / ed. Lviv Yu. L. M.: ANP SSSR. 1988

Rean A.A., Baranov A.A. (1997). Factors of teachers' stress resistance. /Questions of psychology. № 1.P.46-54.

Rupert PA, Stevanovic P. \& Hunley HA (2009). Work-family conflict and burnout among practicing psychologists. Professional Psychology: Research and Practice, 40(1), $\quad 54$ 61.https://doi.org/10.1037/a0012538

Vodopyanova N.E. (2001). The "burnout" syndrome in the professions of the "man-man" system. SPb.: Press.

Zaychikova T.V., Kovalchuk O.S., Fedosova G.L., Filatova O.F., Phil O.A. (Ed.) (2004). Research of the syndrome of "professional burnout" of teachers. K.: Millennium. 